\title{
Mathematics in mathematics education
}

AUTHOR:

Jill Adler ${ }^{1}$

\section{AFFILIATION:}

${ }^{1}$ Division of Mathematics

Education, School of Education,

University of the Witwatersrand,

Johannesburg, South Africa

\section{CORRESPONDENCE TO: Jill Adler}

EMAIL:

jill.adler@wits.ac.za

\section{KEYWORDS:}

mathematics teaching; teacher education; undergraduate curriculum; school mathematics curriculum

\section{HOW TO CITE:}

Adler J. Mathematics in mathematics education. S Afr J Sci. 2017;113(3/4), Art. \#a0201, 3 pages. http://dx.doi. org/10.17159/sajs.2017/a0201

(C) 2017. The Author(s). Published under a Creative Commons Attribution Licence.
What role does mathematics play in the teaching and research of some or all of the 'disciplines' of mathematics education, science education and the social sciences? This question was that to which I was asked to respond at the Academy of Science of South Africa's workshop on the mathematical sciences, held in September 2016. As suggested by the title, my focus here is on mathematics education, which is my field of expertise. An underlying interest or concern of participants in the workshop was what was offered in undergraduate mathematics at university, and how this did (or did not) support the ever-widening role mathematics is playing across disciplines. In addition, there were questions about the place and nature of undergraduate mathematics in the preparation for numerous diverse careers.

The workshop took place over 2 days, and mine was the last of five presentations, following that of mathematics in the earth and biological sciences, economical sciences, engineering and physical sciences, and the mathematical sciences itself. Each presentation was followed by discussion in smaller groups and then plenaries in which the different groups shared key points of discussion. Each of the first four presentations is also the focus of a separate Invited Commentary in this issue. Together they provide a wealth of insight into developments in research in engineering, biology, economics and mathematics, and the implications of these for an undergraduate curriculum in the mathematical sciences.

I was struck during the workshop discussions that the career of a mathematics teacher did not explicitly enter the landscape of possible careers emerging from studying mathematical sciences at university. Yet there was considerable attention to the limitations of the mathematical knowledge and mathematical ways of thinking of firstyear students across these fields and, by implication, the quality of mathematics teaching in our secondary schools.

Teaching and research in mathematics teacher education was, appropriately, the planned focus of my talk. I opened my presentation with two critical questions that needed to be considered in the workshop:

1. Where in a discussion of the future of the mathematical sciences in a rapidly changing, challenging and exciting world do we locate the career of a future school mathematics teacher?

2. What does this location mean for mathematical sciences curricula or education at university?

The background document for the workshop was the 2025 review of the mathematical sciences in the USA. ${ }^{1}$ I was curious whether and how preparation of teachers received attention in that review. Indeed there is a section, albeit small, on the importance of teachers for K-12 (kindergarten to Grade 12). It points in particular to countries that perform well in international mathematics assessments like TIMSS and PISA, through which top mathematics school-leavers enter, and might even have to compete for places in, degree programmes, ultimately leading to teaching careers. Perhaps implied in this is a criticism within the USA where, as in South Africa, teaching is not a high status profession. The point here, however, is that in the 2025 review there also is no mention on whether and how the mathematical preparation of teachers is or should be part of a consideration of the undergraduate curriculum in the mathematical sciences. As I think about this issue, I wonder about a similar review of the mathematical sciences in high-performing countries. Would there be a consideration of 'mathematics for teaching' alongside 'mathematics for biology', 'mathematics for finance', and 'mathematics for economics' as had been discussed in the earlier presentations in the workshop? What would be different? What is taken for granted?

As I worked my presentation into this Invited Commentary a few months after the workshop, I was reminded of the recent presentation by the outgoing President of the Mathematical Association of America, Francis Su, entitled 'Mathematics helps people flourish'. It was a wonderful talk - passionate and compelling. His presentation spiralled around a quotation by the French philosopher Simone Weil: 'Every being cries out silently to be read differently'2. Using stories from an inmate in a high-security prison in the USA, who enjoyed and was studying mathematics, and from Weil herself, Su asks: When you think about who is capable of and who wants to do mathematics, who do you think about? As I move into this commentary I wish to pose a similar question to you, the reader: Who do you think about when you consider who is capable of and who wants to be a mathematics teacher? Would you encourage talented undergraduate mathematics students into the profession of teaching?

These are not trivial questions - they are reflections of how knowledge and status works in society, and I thus do not suggest there are simple answers. But, as in the other fields, there is a great deal that we now know from research in mathematics education and from rigorous study of aspects of mathematics that have arisen and been driven by problems in mathematics education. How might this research inform answers to the questions I have posed above?

\section{What do we know from research in mathematics education?}

There is increasing agreement that there is a specificity to the mathematical knowledge that is required and used in the work of teaching, with the implication that this kind of knowledge should be included in pre-service and continuing teacher education. Substantial and influential research on this topic has been carried out at both primary ${ }^{3}$ and secondary ${ }^{4}$ levels, with both works building on Shulman's ${ }^{5}$ seminal work on the distinctive and significant nature of professional knowledge for teaching, particularly what he termed pedagogic content knowledge.

These results and other developments related to mathematics teachers' professional knowledge are described in a recent review of relevant research. ${ }^{6}$ For example, large-scale research studies have found a moderate association between teachers who have appropriate knowledge of mathematics and pedagogical training and improved teaching and learning. Also, if a teacher's advanced mathematical ability exceeds a certain threshold, it produces negligible 
improvements in learner outputs. Furthermore, in terms of the usefulness of what is being taught, it has been found that calculus coursework enhances learner achievement in algebra but not necessarily geometry.

The authors also discuss weaknesses in the field. There is a lack of agreement about definitions and the language used to describe the specificity of mathematical knowledge for mathematics teaching and its basic concepts. There is also a lack of consensus on the boundaries between this knowledge, mathematics itself and mathematics pedagogy, and consequently on the best practices that can be adopted in the education of primary and secondary school maths teachers. The review, of course, encompasses far more than I have reflected here, but the points made are sufficient for the purposes of this commentary.

\section{What do we learn from research in mathematics education?}

The empirical evidence we have begs our attention. A frequently expressed view in South Africa, one that was stated in the discussion groups in the workshop, is that a prospective secondary mathematics teacher needs at least to have succeeded in second-year level pure mathematics at university. What then of the evidence that advanced courses in calculus do not support quality teaching of geometry? Is there support for schoo Geometry in the first two years of an undergraduate pure mathematics degree programme?

We need to also consider the empirical evidence of improved teaching and learning in mathematics being a function of appropriate levels of mathematics and pedagogic training. In any preparation for future teaching careers there thus needs to be appropriate attention to various areas of the school mathematics curriculum and whether and how topics across the undergraduate mathematical sciences courses span them all. In addition, degrees for mathematics teacher preparation also need to attend to pedagogical training.

Third is the overall result that teaching mathematics requires specialised ways of knowing mathematics. However, while this might mean different types and thresholds of mathematical knowledge for teachers at various levels from pre-primary to tertiary education, to date there are not clear descriptions of what these types and thresholds are and so what is 'appropriate' at the various levels.

\section{What are current practices?}

The present routes into secondary teaching mathematics are: a bachelor's degree in (or at least with some) mathematics taught by mathematics departments at university, followed by a Postgraduate Certificate in Education (PGCE) taught by education departments; or a Bachelor of Education degree, with mathematics and education courses taught predominantly in education departments. Both models have their constraints. The former path, in which all specialised mathematical knowledge for teaching is condensed into 1 year in the PGCE, may provide insufficient knowledge of and for teaching geometry, statistics, probability and financial maths, which are part of the school curriculum, but not necessarily the undergraduate mathematics curriculum. As already noted, research has shown that the calculus taught at university does not support the teaching of geometry at school as it does algebra. It is likely the same holds for probability, statistics and financial mathematics, again posing questions for the undergraduate curriculum in the mathematical sciences if it is to provide the appropriate mathematical education of future teachers.

The mathematics taught as part of the BEd has different limitations. If we focus here only on the BEd degree for secondary mathematics teachers, we need to understand that its intake of students is also different. Many students enter the degree having passed mathematics in Grade 12 and with sufficient points for entry, but with mathematical knowledge that is often ritualised. This means they are able to execute procedures, and with some skill, but not able to grasp the mathematical principles underlying these processes. There is thus a need to revisit school mathematics, and do so from an advanced perspective, deepening what prospective teachers know and understand about school mathematics. And this needs to be offered across all the domains that comprise the school curriculum. For example, if you want teachers to be able to think probabilistically, then you need to include in the mathematics programme a course in which the key ideas, concepts and processes that they need to know is offered. And this needs to be done while introducing and developing higher-level mathematics, and courses in relevant pedagogy. This is a far broader curriculum, just mathematically speaking, and thus cannot also provide for depth and extension across domains as in a dedicated 3-year degree in pure mathematics as it currently stands. While the description I offer here is informed by my knowledge of the BEd degree for secondary mathematics teachers at the University of the Witwatersrand, I think the situation will be similar in other universities in South Africa.

This brief description of different forms of pre-service teacher preparation currently offered reveals that the strengths of one route are reflected in the limitations of the other, thus challenging views that promote one or other of these routes as 'the best' preparation for teachers. Here too we confront a problem that does not have clear or immediately visible solutions, particularly in the current South African context in which the performance curve in Grade 12 mathematics is skewed towards poor results, with relatively few learners obtaining $60 \%$.

As a means of thinking further about mathematics in teaching and thus about the mathematical preparation of future mathematics teachers at all levels of schooling, I offer an example of an intervention into secondary mathematics teachers education in South Africa - focused at the transition from Grades 9 to 10 - that I suggest gives practical meaning to the notion of mathematics in mathematics teaching at this mid-secondary level.

\section{A current project with specific focus on mathematics for teaching}

The Wits Maths Connect Secondary (WMCS) project at the University of the Witwatersrand is a linked research and development project seeking to improve the teaching and learning of mathematics in some secondary schools in one province in South Africa, through the professional development of mathematics teachers. The goals are twofold: to improve teachers' mathematics knowledge for teaching and their teaching practices and to study whether and how the intervention impacts learners' learning. ${ }^{7}$

The WMCS professional development programme includes a 16-day mathematics for teaching course focused on mathematics relevant to teaching across the Grades 9 to 10 transition. Teachers attend eight 2-day sessions over the course of a year. Three quarters of each 2-day session focuses on mathematics with the remaining quarter on strategies for teaching. Participating teachers are required to complete independent assignments on mathematics and on teaching mathematics in between each of the 2-day sessions. The course focuses on algebra and functions, with some attention given to geometry and trigonometry. The topics were chosen according to their relative importance within the curriculum, as well as for their potential to leverage learning gains.

In the schools we were working with in the WMCS project, we found many teachers who were teaching Grades 8 and 9 did not and could not teach beyond this level. Many were 'out-of-field' teachers, meaning that they were either specialists in subjects other than mathematics, or had trained perhaps as primary mathematics teachers. Many expressed a lack of confidence in their mathematical knowledge and our research on their teaching showed that their explanations lacked clear focus and coherence.

We thus designed, developed and implemented a course that revisits mathematics that might be considered 'known' to the participants. The ways in which this is done is to deepen, strengthen and extend this existing knowledge. For example, special cases are explored and aspects of mathematics that have been assumed as 'known' are problematised. Connections are made across topics and concepts in the curriculum. New mathematics is also included, to extend teachers beyond the curriculum and the grade level which they are teaching, and so into Grades 10-12 mathematics. The teachers work on their knowledge of key concepts as well as their fluency with relevant mathematical procedures, and both in a context in which mathematical inquiry of these is encouraged and supported through carefully designed mathematical tasks. 
Strategies for teaching in the mathematics teaching component of the course focuses on key elements of mathematics teaching practices. I do not provide detail here and refer readers to articles related to this work. ${ }^{8,9}$

The impact of the professional development course has been studied by assessing the learning gains among a cohort of 609 pupils in five schools over an academic year (2013). The major result of this study is that learners taught by the teachers who had taken the course significantly outperformed the learners in the same schools taught by teachers who had not taken the course. ${ }^{10}$ This was a pilot study, and the results are only indicative. Nevertheless, the implications are that enhancing teachers' mathematical knowledge for teaching can lead to improvements in learning.

The point of the discussion of this intervention and its research is that the course is organised around a selection of mathematics for teachers that are considered 'appropriate' for teachers and teaching at those grade levels. The course is deliberate in its own pedagogic strategies and creates possibilities for teachers to move from their ritualised to more elaborated mathematical knowledge. While the mathematics content selection and how it is organised for teachers' learning extends beyond the levels they teach (Grades 8 and 9), these do not reach levels of undergraduate mathematics.

\section{Undergraduate mathematics with mathematics teacher education}

The WMCS study is not focused at the senior secondary level (Grades 10-12). However, there are implications for the shape of a well-rounded undergraduate curriculum in the mathematical sciences if it is to include mathematics teacher education in its landscape. A mathematics for teaching course for teachers teaching Grades 11 and 12 mathematics would of course have a different selection of mathematics. I suggest, nevertheless, that similar principles should hold. Revisiting key concepts in secondary school mathematics is important for prospective teachers. This kind of mathematics study needs to be added to courses in advanced mathematics, to offer prospective teachers opportunities to learn new mathematical knowledge (e.g. calculus) and appreciate advances in the discipline. What then about advanced courses in geometry, probability, statistics and financial mathematics? These are all topics in the secondary curriculum, and all are part of the mathematical sciences, but not necessarily part of a considered degree programme suited to the needs of prospective teachers.

Broadening curricula by offering a wider range of mathematics topics inevitably has consequences for working within and across the mathematical sciences. And we have not yet included the necessary focus needed on pedagogical training. This tension between a broader curriculum and depth in disciplinary specialisation is one that will not be easily resolved, but it is one that needs attention. And then there are implications for who teaches all these different elements of professional knowledge for mathematics teachers, for example courses in revisiting school mathematics. Mathematicians? Mathematics teacher educators? The notion of mathematics in mathematics teaching as including spe- cialised knowledge also suggests that we would need to nurture the identities and specific expertise of 'educators' who may foster the next generation of maths teachers. There is, indeed, much to do, in what is a collaborative task for those in both the mathematical sciences and mathematics education.

\section{Acknowledgements}

This work is based on the research supported by the South African Research Chairs Initiative of the Department of Science and Technology and the National Research Foundation (NRF) of South Africa (grant number 71218). Any opinion, finding and conclusion or recommendation expressed in this material is that of the author and the NRF does not accept any liability in this regard.

\section{References}

1. National Research Council of the National Academies. The mathematical sciences in 2025. Washington DC: The National Academies Press; 2013. https://doi.org/10.17226/15269

2. Francis S. Mathematics for human flourishing [homepage on the Internet]. c2017 [cited 2017 Feb 24]. Available from: https://mathyawp.wordpress. com/2017/01/08/mathematics-for-human-flourishing/

3. Ball DL, Thames MH, Phelps G. Content knowledge for teaching: What makes it special? J Teach Educ. 2008;59(5):389-407. https://doi. org/10.1177/0022487108324554

4. Baumert J, Kunter M, Blum W, Brunner M, Voss T, Jordan A, et al Teachers' mathematical knowledge, cognitive activation in the classroom, and student progress. Am Educ Res J. 2010;47(1):133-180. https://doi. org/10.3102/0002831209345157

5. Shulman L. Knowledge and teaching: Foundations of a new reform. Harvard Educ Rev. 1987;57(1):1-22. https://doi.org/10.17763/ haer.57.1.j463w79r56455411

6. Hoover M, Mosvold R, Ball D, Lai Y. Making progress on mathematical knowledge for teaching. The Mathematics Enthusiast. 2016;13:12-14.

7. Adler J. The research and development learning curve 2010-2014: Report of the Wits FRF Mathematics Chair and the Wits Maths Connect Secondary (WMCS) project [document on the Internet]. c2014 [cited 2017 Feb 24]. Available from: http://www.nrf.ac.za/sites/default/files/documents/Professor\%20Adler\%20 CoP\%20presentation\%202014.pdf

8. Adler J, Venkat H. Teachers' mathematical discourse in instruction: Focus on examples and explanations. In: Rollnick M, Venkat H, Loughran J, Askew M, editors. Exploring content knowledge for teaching science and mathematics. London: Routledge; 2014. p. 132-146.

9. Adler J, Ronda E. Mathematical discourse in instruction matters. In: Adler J, Sfard A, editors. Research for educational change: Transforming researchers insights into improvement in mathematics teaching and learning. Abingdon: Routledge; 2017. p. 64-81

10. Pournara C, Hodgen J, Adler J, Pillay V. Can improving teachers' knowledge of mathematics lead to gains in learners' attainment in mathematics? S Afr J Educ. 2015;35(3):10. https://doi.org/10.15700/saje.v35n3a1083 